\title{
The Clinical Genetics of Hemophilia B (Factor IX Deficiency)
}

\author{
Connie H Miller (D) ${ }^{1,2}$ \\ 'Division of Blood Disorders, National \\ Center on Birth Defects and \\ Developmental Disabilities, Centers for \\ Disease Control and Prevention, Atlanta, \\ GA, USA; ${ }^{2}$ Synergy America, Inc., Duluth, \\ GA, USA
}

Correspondence: Connie H Miller Division of Blood Disorders, National Center on Birth Defects and Developmental Disabilities, Centers for Disease Control and Prevention, 1600 Clifton Road, MS D-02, Atlanta, GA, 30333, USA

$\mathrm{Tel}+\mid$ 50l 408-6239

Email cmiller2@cdc.gov

\begin{abstract}
Hemophilia B (HB) is a bleeding disorder caused by deficiency of or defect in blood coagulation factor IX (FIX) inherited in an X-linked manner. It results from one of over 1000 known pathogenic variants in the FIX gene, F9; missense and frameshift changes predominate. Although primarily males are affected with $\mathrm{HB}$, heterozygous females may have excessive bleeding due to random or non-random $\mathrm{X}$ chromosome inactivation; in addition, homozygous, compound heterozygous, and hemizygous females have been reported. Somatic and germinal mosaicism for $F 9$ variants has been observed. Development of antibodies to FIX treatment products (inhibitors) is rare and related to the type of causative variant present. Treatment is with products produced by recombinant DNA technology, and gene therapy is in clinical trials. Genetic counseling with up-to-date information is warranted for heterozygotes, potential heterozygotes, and men and women affected with HB.
\end{abstract}

Keywords: factor IX, hemophilia B, genetics, hematology

\section{Introduction}

Hemophilia $\mathrm{B}$ is a genetic disorder of impaired blood coagulation that causes excessive bleeding, particularly following trauma or medical procedures, which can be life-threatening if untreated. A hallmark of hemophilia is bleeding within joints and muscles that in the past often resulted in disability. Today the disorder is manageable by replacing the missing blood coagulation factor, factor IX (FIX), using recombinant drugs that are often administered by patients or family members to prevent or treat bleeding. Among the many known bleeding disorders, the term hemophilia is reserved for two X-linked disorders, hemophilia A (HA) and hemophilia $\mathrm{B}(\mathrm{HB})$, which are almost indistinguishable clinically. ${ }^{1}$ Since the gene for FIX, named F9, was cloned in $1982,2,3$ more than 1000 variants causing HB have been reported. ${ }^{4,5}$ Genotype-phenotype associations have been made that clarify some of the basic characteristics of the disorder. The appearance of HB in females is also better understood based on developments in X-chromosome genetic testing.

\section{History}

Hemophilia is readily recognizable in historic literature because of its striking clinical features and inheritance pattern. Hemophilia was mentioned in Rabbinic writings of the 5 th century. ${ }^{6}$ The first medical report was in 1803 by John C. Otto of Philadelphia. ${ }^{7}$ Yet, not until 1952 was it recognized that there are actually two forms of hemophilia with the same distinctive inheritance pattern: hemophilia A, or 
classic hemophilia, and hemophilia B, called Christmas disease. Christmas disease was named for the first patient in which it was described. ${ }^{8}$ When plasmas from this patient and six others were mixed with plasma from the majority of patients with hemophilia, their prolonged clotting was corrected, indicating that they did not have the same defect, an example of genetic complementation. The clotting factor deficient in hemophilia A was named factor VIII (FVIII) and that deficient in HB, once called Christmas factor, was named factor IX (FIX). ${ }^{9}$ The famous hemophilia family descended from Queen Victoria of England has been shown to have HB; their specific mutation in the $F 9$ gene was identified in the recently discovered remains of the Russian royal family. ${ }^{10}$

\section{Clinical Features}

Hemophilia is typically suspected in an infant with intracranial hemorrhage or bleeding post circumcision; however, these occurred in only $19 \%$ and $27 \%$, respectively, of 404 males with HA or HB who were attending US hemophilia treatment centers (HTCs) by age $2 .^{11}$ The initial bleeding symptoms reported most often were iatrogenic (heel stick, intramuscular injection, venipuncture) and traumatic (oral mucosa, soft tissue, joint) episodes. Among this young group, 75\% were diagnosed within the first month of life; however, $63 \%$ were diagnosed due to family history of hemophilia and only $35 \%$ due to bleeding. Some may have escaped bleeding because the diagnosis occurred prior to procedures, such as circumcision, particularly when family history was known. In children without a known family history of HB, diagnosis may be delayed until excessive bruising occurs during crawling or walking. Although males are affected much more often, females may have the disorder, as discussed below, and apparent female sex does not exclude the diagnosis. ${ }^{12}$

Both $\mathrm{HA}$ and $\mathrm{HB}$ will result in prolongation of the activated partial thromboplastin time (APTT), except in the milder forms. HB is diagnosed by measurement of FIX activity in plasma using a one-stage clot-based or chromogenic substrate assay. The results are expressed as \% of normal, which is equivalent to units per deciliter $(\mathrm{U} / \mathrm{dL})$ or international units (IU) per deciliter when quantitated by comparison to an international plasma standard. ${ }^{13} \mathrm{HB}$ is defined as severe if FIX activity is less than $1 \%(<1 \mathrm{U} / \mathrm{dL})$, moderate if the level is $1-5 \%(1-5 \mathrm{U} / \mathrm{dL})$, and mild if the level is greater than $5 \%$ but less than $40 \%(>5$ to $<40 \mathrm{U} /$ $\mathrm{dL}$ ), although some sources use $<50 \%$ rather than $<40 \%$ to define the hemophilia range. ${ }^{14}$ FIX activity may also be low in the following circumstances: normal neonates and premature infants; vitamin $\mathrm{K}$ deficiency at any life stage; inherited deficiency of vitamin K-dependent factors (an autosomal disorder); anticoagulant therapy with vitamin $\mathrm{K}$ antagonists, such as warfarin or coumadin; and liver disease. These conditions, however, will also result in a decrease in other vitamin K-dependent factors, such as factor VII, and result in prolongation of the prothrombin time in addition to the APTT. FIX may also be measured as FIX antigen by immunologic methods; this test will be normal in most acquired deficiencies but also is normal in some forms of $\mathrm{HB}$ and is not often available clinically.

Diagnosis of HB in the neonate may be difficult due to the low levels of FIX seen in unaffected infants. Levels do not reach the normal adult range until six months of age. ${ }^{15}$ In infants, severe disease can be detected by carefully controlled FIX assays, but mild or moderate levels may be difficult to interpret. Laboratories less experienced at measuring low FIX levels may prefer to use reference laboratories or referrals to specialized hemophilia treatment centers to avoid misdiagnosis. The analysis of the F9 gene for a causative variant can be used to confirm the diagnosis.

Severe HB may result in spontaneous bleeding into joints and muscles, which if untreated causes intense pain, immobility, and eventually permanent joint damage. Prompt treatment when bleeding occurs, termed episodic treatment, can reduce these effects; however, today's standard of care for individuals with severe hemophilia is prophylactic treatment, providing frequent doses of factor to prevent bleeding episodes, which can reduce the longterm effects of the disease. ${ }^{16}$ In moderate HB, similar bleeding may occur; however, it is rarely spontaneous except in areas with previous damage. Bleeding in mild $\mathrm{HB}$ is most often the result of injury or medical or dental procedures. All forms will need pretreatment to normalize FIX levels for surgery or dental procedures. Treatment today is given by recombinant FIX products, some of which have been altered to prolong FIX half-life in the circulation and are referred to as extended half-life products. ${ }^{17}$ Treatment intervals are individually determined to maintain protective levels of FIX. ${ }^{18}$ In an international study conducted from 2015 to 2018, prophylactic treatment was received by $64 \%$ of severe patients, $8.7 \%$ of moderate patients, and no mild patients; severe patients averaged 57 infusions per year, moderate 12 infusions, and mild 5 infusions. ${ }^{19}$ In the United States, health care costs among patients with $\mathrm{HB}$ averaged 25 times those of 
Table I Frequency of Hemophilia A and Hemophilia B Patients by Severity Among Patients Attending US Hemophilia Treatment Centers ${ }^{24}$

\begin{tabular}{|c|c|c|c|c|c|}
\hline \multirow[t]{2}{*}{ Type } & \multirow[t]{2}{*}{$\mathbf{n}$} & \multicolumn{4}{|c|}{ Severity n (\%) } \\
\hline & & Severe & Moderate & Mild & Unknown \\
\hline Hemophilia A & 16,642 & 8011 (48.2) & $3319(19.9)$ & $5024(30.2)$ & $288(1.7)$ \\
\hline Hemophilia B & 5106 & | 467 (28.7) & $2108(41.3)$ & I423 (27.9) & $108(2.1)$ \\
\hline
\end{tabular}

Notes: Adapted with permission from Soucie JM, Miller CH, Dupervil B, Le B, Buckner TW. Occurrence rates of haemophilia among males in the United States based on surveillance conducted in specialized haemophilia treatment centres. Haemophilia. 2020;26(3):487-493. Published 2020. This article is a U.S. Government work and is in the public domain in the USA. ${ }^{24}$

matched controls, due primarily to the cost of factor replacement therapy. ${ }^{20}$ Some methods of gene therapy for HB are currently in clinical trials, as discussed below. ${ }^{21}$

It has long been suggested that HB is clinically less severe than HA. ${ }^{22,23}$ This perception may be partially due to the fact that the distribution of severity is different in the two disorders (Table 1). Among patients treated at US HTCs, those with severe disease make up $48.2 \%$ of HA patients but only $28.7 \%$ of those with HB. ${ }^{24}$ The differences go beyond frequencies, however. Studies have shown that patients with HB had fewer hemarthroses and less joint damage, fewer bleeding episodes, and lower rates of prophylactic treatment than those with HA, as reviewed by Castaman. ${ }^{1}$ The effects of the two diseases are also influenced by their mutation profiles. $^{22}$ Severe HA results more often from null variants producing no gene product, while severe HB includes a higher proportion of missense variants. ${ }^{1}$ Because of this difference, HB patients are also less likely than those with HA to produce antibodies that interfere with the function of clotting factor replacement (inhibitors). In the United States, $2 \%$ of $3785 \mathrm{HB}$ patients enrolled in a national surveillance program had inhibitors, including $4.9 \%$ of those with severe $\mathrm{HB}, 0.5 \%$ of those with moderate $\mathrm{HB}$, and $0.1 \%$ of those with mild $\mathrm{HB}^{25} \mathrm{HB}$ patients with inhibitors, unlike those with HA, often develop anaphylaxis ${ }^{26}$ or nephrotic syndrome $^{27}$ when treated with FIX-containing products. Patients with inhibitors to FIX usually require alternative treatments to achieve hemostasis, such as recombinant factor VIIa. $^{28}$ The reduction of antibody response by frequent factor doses (ie, immune tolerance induction) is less successful in HB than in HA. ${ }^{29}$

\section{Epidemiology}

$\mathrm{HB}$ is less common than HA. An international study ${ }^{30}$ found the prevalence of $\mathrm{HA}$ to be 17.1 per 100,000 males in the population, while the prevalence of HB was 3.8 males per 100,000 ; thus, HB affects $18 \%$ of people with hemophilia. The incidence, or prevalence at birth, was 23.2 per 100,000 males for HA and 4.7 per 100,000 males for HB, making the incidence of $\mathrm{HB}$ about one-fifth that for HA. Similar figures have been obtained from US HTCs, although the prevalence of HB in the United States was slightly higher, making up $24 \%$ of those with hemophilia. ${ }^{24} \mathrm{HB}$ has been observed to be more common in some portions of the US; ${ }^{24}$ this is thought to be due to a founder effect, discussed below. When studied on a country-by-country basis, HB prevalence was found to vary among countries and to be higher in higher-income countries. It also appeared to increase over time. Both of these characteristics may be due to increased access to health care, longer survival, and better data collection. ${ }^{31}$

\section{Inheritance}

HA and HB both exhibit X-linked inheritance because the gene for FVIII, called $F 8$, and the gene for FIX, called $F 9$, are located on the long arm of the $\mathrm{X}$ chromosome. In the sex determination mechanism of humans, females have two $\mathrm{X}$ chromosomes, and males have one $\mathrm{X}$ chromosome and one $\mathrm{Y}$ chromosome. Because most genes on the $\mathrm{X}$ chromosome have a single allele on the $\mathrm{X}$ and no comparable allele on the $\mathrm{Y}$ chromosome, defects in $\mathrm{X}$ chromosome genes are apparent in the male, who is termed hemizygous and has the full phenotype of the disease. Females have two alleles for $\mathrm{X}$ chromosome genes, so a defect in a single allele may be compensated by a normal allele. The phenotype of such heterozygous females, however, is complicated by the normal process of $\mathrm{X}$ chromosome inactivation, discussed below, and more complex genetic situations, which rarely may produce hemophilic females. ${ }^{12}$ It is this X-linked inheritance pattern, which has been recognized for centuries, that is usually characterized by unaffected heterozygous females (carriers) transmitting hemophilia to one-half of their male offspring and heterozygosity to one-half of their daughters. Men with hemophilia transmit a hemophilia allele to all of their daughters and none of their sons, who get their Y chromosome only.

"Sporadic" cases of hemophilia appear when there is no known family history of the disease. They may be due to 1) 
a new hemophilia allele appearing by mutation in the egg or sperm cell producing the affected child, in which case the mother is not heterozygous; 2) a new mutation in the egg or sperm cell producing the mother, who is thus heterozygous; 3) a heterozygous mother whose family history was not known, due either to lack of information or the occurrence of few male births in the family; or 4) maternal mosaicism. ${ }^{32}$ Approximately one-third of births of males with $\mathrm{HB}$ are reported to be sporadic; however, many mothers are subsequently shown to be heterozygous or mosaic by testing or birth of further affected sons. In a study of $240 \mathrm{HB}$ patients, ${ }^{33} 149$ (62\%) were familial cases; of the 91 mothers with no family history, 42 (46\%) subsequently had more affected offspring, proving themselves heterozygous or mosaic, and approximately $85 \%$ of the remaining 49 were found heterozygous by testing, indicating that overall, $92 \%$ of mothers of sporadic cases were actually heterozygous in reproductive cells. Cases born to truly non-heterozygous mothers are quite rare; and given the possibility of mosaicism, discussed below, non-heterozygosity cannot be proven with certainty in a sporadic case. ${ }^{32}$

\section{Factor IX Gene and Protein}

The FIX gene, F9, is located at Xq27.1 and includes 33.5 kilobases (kb) of DNA with 8 exons (Figure 1). The $2.7 \mathrm{~kb}$
FIX messenger RNA produces a single-chain precursor protein of 461 amino acids. ${ }^{34}$ The protein includes a signal peptide, a propeptide, a glutamic acid (Gla) domain, two epidermal growth factor-like (EGF) domains, a linking sequence, and the catalytic (protease) domain. Twelve Gla residues require vitamin K-dependent gammacarboxylation. The first EGF domain undergoes betahydroxylation at residue Asp64, addition of di- or trisaccharide, and formation of three disulphide bonds. After the cleavage of a pre-pro leader, the mature protein has 415 amino acids. ${ }^{34}$ During activation, the cleavage of two peptide bonds releases an activation peptide of 35 amino acids. Activated factor IX (FIXa) consists of a light chain, including the Gla and EGF domains, and a heavy chain, the catalytic domain, and has serine protease activity.

FIX is produced in hepatocytes and is similar in structure to other vitamin K-dependent proteins, such as factors II, VII, and $\mathrm{X}^{35}$ In the coagulation process, FIX is converted to FIXa by activated FVII and tissue factor through the extrinsic pathway or by activated factor XI through the intrinsic pathway. FIXa converts factor X to activated FX (FXa) in the presence of its cofactor FVIII. FXa then converts prothrombin to thrombin to facilitate the formation of the fibrin clot.

\section{EXONS}

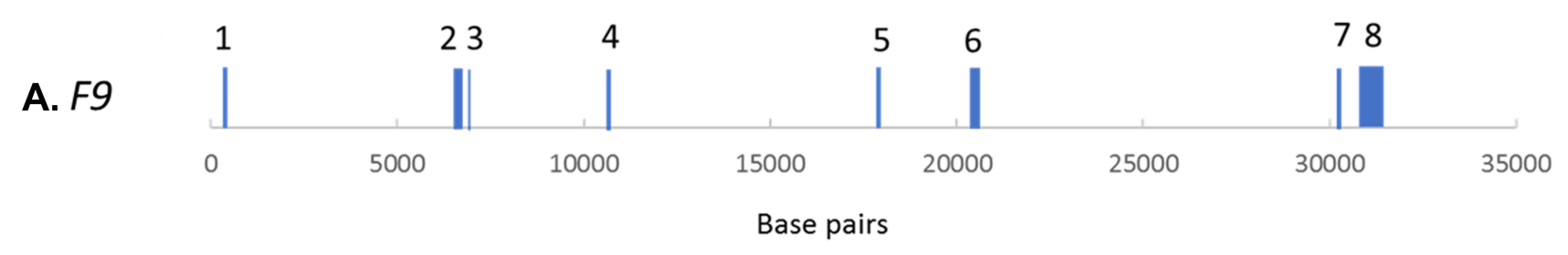

B. FIX

\begin{tabular}{|c|c|c|c|c|c|c|c|c|}
\hline Signal & Pro & Gla & H & EGF1 & EGF2 & L & Act & Serine Protease \\
\hline $1-28$ & $29-46$ & $47-86$ & & $93-130$ & $131-173$ & & $192-226$ & $227-461$ \\
\hline
\end{tabular}

Amino Acids

$87-92$

174-191

C. FIXa

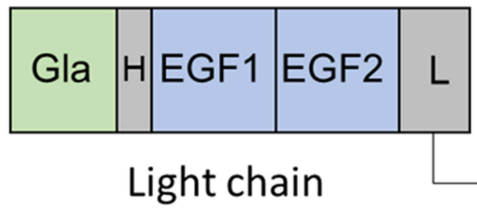

Serine Protease

Heavy chain

Figure I Diagram of factor IX (FIX) gene and protein structure. (A) FIX gene (F9). (B). FIX protein showing amino acids numbered by Human Genome Variation Society nomenclature. (C). Activated FIX (FIXa). Domains include signal peptide (Signal), propeptide (Pro), gamma-carboxyglutamic acid (Gla), hydrophobic segment (H), epidermal growth factor (EGF) I, EGF 2, linker peptide (L), activation peptide (Act), serine protease. 


\section{F9 Variants}

Terminology for gene changes has evolved from the use of the terms "mutation" and "polymorphism" to a preference for the term "variant" with qualifiers indicating what is known about the ability of the change to cause disease. Standards and guidelines produced by the American College of Medical Genetics and Genomics and the Association for Molecular Pathology in $2015^{36}$ have been applied specifically to bleeding disorders by Gomez et al. ${ }^{32}$ Under these guidelines, variants in the structure of the $F 9$ gene that are disease-causing are termed pathogenic, while variants that do not affect FIX function and occur in the normal population are termed benign. Two online databases record reported $F 9$ variants. The Factor IX Gene $(F 9)$ Variant Database at http://www.factorix.org includes both pathogenic and benign variants with individual patient data reported in the literature or submitted. ${ }^{4}$ The CDC Hemophilia B Mutation Project (CHBMP) at https://www. cdc.gov/ncbddd/hemophilia/champs.html lists variants reported to cause HB by their first literature report. ${ }^{5}$ Both include information on severity and inhibitor occurrence, when available. The Factor IX Gene ( $F 9$ ) Variant Database also includes structural models for missense variants. The variants listed in the Factor IX Gene (F9) Variant Database (Table 2A) are classified by DNA change. Point mutations make up $76.7 \%$ of disease-causing variants in $F 9$, followed by deletions at $17.2 \%$, with other variant types including fewer than $5 \%$ of variants. Table $2 \mathrm{~B}$ shows the distribution of variant types currently reported in CHBMP, which are classified by their effect on the protein. Missense variants make up $58.1 \%$ of those reported, followed by frameshifts at $16.1 \%$, splice site changes at $9.4 \%$, and nonsense variants at $8.0 \%$. Other variant types each make up fewer than $5 \%$ of variants observed.

Inhibitors to FIX occur primarily in patients with $F 9$ deletions, frameshifts, and nonsense mutations, which result in truncated or absent FIX protein; only one missense and two splicing variants have been reported in patients with inhibitors. ${ }^{4}$

One form of HB is unique in that FIX levels are low in early life and rise at puberty: hemophilia B Leyden, ${ }^{37}$ which is caused by variants in the promoter region of F9. This apparent "cure" of HB with age was originally thought to be related to androgen receptors, but increases in FIX have been seen in some patients prior to puberty ${ }^{38}$ and in heterozygous women, ${ }^{39}$ suggesting a sexindependent mechanism.
Table 2 Unique F9 Variants Reported to Cause Hemophilia B by Variant Type Classified by A. Type of Gene Change from Factor IX Gene (F9) Variant Database [http://www.factorix.org] and B. Type of Protein Change from CDC Hemophilia B Mutation Project [https://www.cdc.gov/ncbddd/hemophilia/champs.html

\begin{tabular}{|l|r|r|}
\hline A. Type of Gene Change ${ }^{80}$ & $\begin{array}{r}\text { Number of } \\
\text { Variants }\end{array}$ & $\begin{array}{r}\% \text { of } \\
\text { Variants }\end{array}$ \\
\hline Point mutation & 800 & 76.7 \\
Deletion & 179 & 17.2 \\
Insertion & 37 & 3.5 \\
Indel & 17 & 1.6 \\
Duplication & 5 & 0.5 \\
Complex & 5 & 0.5 \\
Total & 1043 & 100.0 \\
\hline B. Type of Protein Change ${ }^{81}$ & Number of & $\%$ of \\
& Variants & Variants \\
\hline Missense & 657 & 58.1 \\
Frameshift & 182 & 16.1 \\
Splice site change & 106 & 9.4 \\
Nonsense & 91 & 8.0 \\
Large structural change (>50 base & 33 & 2.9 \\
pairs) & & \\
Promoter & 25 & 2.2 \\
Small structural change (in-frame, & 23 & 2.0 \\
<50 base pairs) & & \\
3' untranslated region $_{\text {Synonymous }}$ & 4 & 0.4 \\
Total & 10 & 0.9 \\
\hline
\end{tabular}

Notes: Adapted with permission from UCL. Factor IX Gene (F9) Variant Database. Available from: http://www.factorix.org/statistics.html.php. ${ }^{80}$ Data from Centers for Disease Control and Prevention CHBMP F9 Mutation List. ${ }^{81}$

\section{Heterozygous Females (Carriers)}

Females who are heterozygous for HB-causing $F 9$ variants have a wide range of FIX levels (Figure 2) due to the phenomenon of X-chromosome inactivation (XCI), which in humans serves to inactivate one $\mathrm{X}$ chromosome in each somatic cell of a female and equalize the dosage of $\mathrm{X}$ chromosome genes between males and females. XCI occurs randomly early in development and results in clonal populations of cells with either the paternal or the maternal $\mathrm{X}$ inactive. This is not obvious unless a disease gene is involved. If the allele from one parent is defective, XCI, due to its random nature, can result in all $\mathrm{X}$ chromosomes with the defective allele being expressed or all of those with the normal allele being expressed, as shown at the extreme ends of the distribution in Figure 2, or any combination in between. This results in a substantial number of females heterozygous for HA or HB having factor levels 


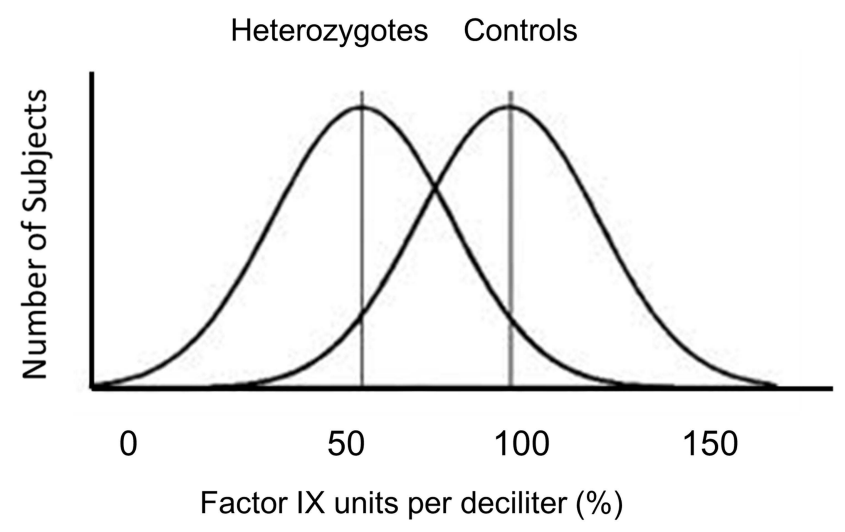

Figure 2 Distributions of factor IX activity in women heterozygous for variants causing hemophilia B (heterozygotes) and for women not having variants causing hemophilia (controls). Reproduced with permission from Miller CH, Bean CJ. Genetic causes of haemophilia in women and girls. Haemophilia. 2020;27(2):el64-el79. () Published 2020. This article is a U.S. Government work and is in the public domain in the USA. ${ }^{12}$

below the hemostatic range of about $40 \%$. These women and girls will have the bleeding symptoms typically seen in males with hemophilia of the same factor level, such as hemarthrosis and muscle bleeding, and should be considered to have hemophilia. Likewise, heterozygotes for HB may have FIX levels that are completely normal; such women are undetectable by measurement of FIX level alone. Thus, the ability to detect HB heterozygotes was limited prior to the availability of gene sequencing. Hemophilia heterozygotes have higher rates than nonheterozygotes of excessive bleeding with tooth extraction, surgery, and delivery, as recently summarized. ${ }^{12}$ Menorrhagia is often present but is not invariable. ${ }^{40,41}$ On a standardized bleeding assessment tool, the International Society on Thrombosis and Haemostasis Bleeding Assessment Tool, women heterozygous for HA or HB scored higher than controls in the categories of cutaneous, minor wound, oral cavity, menorrhagia, hemarthrosis, post dental, postsurgical, and postpartum bleeding, and there was a significant inverse correlation between factor level and bleeding score. ${ }^{42}$

A female is considered an obligate heterozygote for $\mathrm{HB}$ if she is the mother of a $\mathrm{HB}$ son with another relative with $\mathrm{HB}$, the mother of more than one HB son, or the daughter of a man with HB. Other women related to a male with $\mathrm{HB}$ through maternal ties are potential heterozygotes. Most HB heterozygotes within families transmitting $\mathrm{HB}$ can be detected by sequencing of the $F 9$ gene, preferably after the diseasecausing variant in the affected male has been identified. F9 deletions and duplications are not evident in the heterozygous state by sequencing and require Multiplex Ligation-
Dependent Probe Amplification $\left(\mathrm{MLPA}^{\circledR}\right)$ or similar gene dosage analysis for detection. ${ }^{43}$ Each heterozygous or potentially heterozygous female is advised to have her factor IX level measured and bleeding history assessed at the time of genetic diagnosis and receive advice regarding her need for treatment and genetic counseling about available reproductive options and delivery planning, as discussed below.

Heterozygotes for HB are heterogeneous in their gene expression due to XCI; this does not usually affect detection of the heterozygous state by testing of DNA from blood cells. Rarely, however, individuals may have different genotypes in blood cells and reproductive cells and are mosaic, as discussed below. This occurrence makes it impossible to assure a woman with no family history of $\mathrm{HB}$ that she is not heterozygous for $\mathrm{HB}$ with complete certainty. This needs to be communicated when test results are discussed.

\section{Females with Hemophilia B}

Although females with severe or moderate HB are quite rare, women and girls made up $24 \%$ of individuals with mild HB seen for care at US HTCs. ${ }^{44}$ The genetic causes of hemophilia in those women and girls among whom a causative variant has been identified have recently been reviewed. ${ }^{12}$ They include homozygosity (two copies of the same hemophilia-causing variant), compound heterozygosity (two different hemophilia-causing variants in trans), hemizygosity (a single hemophilia-causing variant with no normal allele), and heterozygosity (one hemophiliacausing variant and one normal allele). Homozygosity was reported in a 9-year-old girl with FIX $<1 \%$ who inherited a F9 variant, c.484C $>$ T; p.Arg162*, from both a heterozygous mother and a father with severe HB who were related. ${ }^{45}$ Compound heterozygosity was seen in a girl with moderate HB (FIX 1\%) whose mother was demonstrated to have somatic mosaicism, with a $F 9$ variant present in $5 \%$ of leucocytes but $10-30 \%$ of buccal and urogenital cells and normal FIX, while a second mutation occurred de novo on her unaffected father's $\mathrm{X}$ chromosome. Her sister received her mother's variant only and had 7\% FIX. ${ }^{46}$ Hemizygosity was identified in five females with HB: three had Turner syndrome $(45, \mathrm{X})$, two of whom were mosaic for cell lines missing an $\mathrm{X}$ chromosome; ${ }^{40,47,48}$ and two had X-chromosome deletions that included their normal $F 9$ alleles: 46,X,del(X) $(\mathrm{q} 26.3 \mathrm{q} 28)^{49}$ and 46,X,del(X)(q27). ${ }^{40}$ Heterozygosity with preferential inactivation of abnormal $\mathrm{X}$ chromosomes was seen in three families. Two involved $\mathrm{X} /$ autosome 
translocations with deletion of part of $F 9 . .^{50,51}$ In one case, maternal uniparental disomy of Xq27qter caused the $\mathrm{X}$ with the normal $F 9$ allele to be inactivated. ${ }^{52}$ Presence of other disease genes on the $\mathrm{X}$ chromosome has been reported to cause preferential XCI leading to HA, but no such cases have been described in $\mathrm{HB}^{12}$

As noted above, genetically proven heterozygotes with no overt $\mathrm{X}$ chromosome structural defect may have FIX levels diagnostic of HB. Eighteen of these have been studied in depth, with twelve demonstrated to have excessively skewed $\mathrm{X}$-inactivation patterns, as reviewed. ${ }^{12}$ A pair of monozygotic twins had FIX levels of $<1 \%$ and $15 \%,{ }^{53}$ and a pair of dizygotic twins with $2 \%$ and $24 \%$ FIX showed 99:1 and 65:35 parental X activity, respectively. $^{54}$ It has been suggested that undetected small structural changes in the $\mathrm{X}$ chromosome may account for some of these cases. ${ }^{54-56}$ Changes to the Xist gene resulting in familial skewed $\mathrm{X}$ inactivation have also been suggested for $\mathrm{HA},{ }^{57}$ and the same mechanism could apply to HB.

Evaluation of a female presenting with a low FIX level requires an initial assessment of personal and family history of bleeding; if no family history of HB is found, then further evaluation would include testing for other vitamin K-dependent factors (factors II, VII, and X) to rule out congenital or acquired combined deficiency and testing of FIX levels in both parents. Factor IX inhibitors causing acquired $\mathrm{HB}$ are quite rare but could be considered. $F 9$ analysis for HB-causing variants should be conducted by sequencing and MLPA ${ }^{\circledR}$, which is necessary to detect gene deletions and duplications in females. For those with FIX less than $5 \%$, a karyotype with high-resolution examination of the $\mathrm{X}$ chromosome, paternity testing, and $\mathrm{X}$ inactivation studies are indicated. The differential diagnosis for a female with low FIX includes vitamin $\mathrm{K}$ deficiency, combined deficiency of vitamin K-dependent factors, acquired $\mathrm{HB}$, and physiologic low level in a neonate.

\section{Mutation and Mosaicism}

Hemophilia was used in the first studies of the mutation rate of human genes. ${ }^{58,59} \mathrm{HB}$ has been used to demonstrate a higher rate of mutation in spermatogenesis than oogenesis $^{60,61}$ as well as the genetic concept of founder effect. Founder effect occurs when a disease-causing variant is present in one of the small number of founding members of an isolated population and thus is transmitted to a higher proportion of individuals than in other populations. Only three $F 9$ variants were suggested to account for $25 \%$ of the HB patients in the United States. ${ }^{62}$ Two of these accounted for $19 \%$ of $\mathrm{HB}$ patients in Mexico, however with different haplotypes, suggesting independent origins. ${ }^{63}$ In Ireland, a different group of three HB variants made up 51\% of HB cases, including an HB Leyden variant. ${ }^{64}$ No such effect was seen in Sweden ${ }^{65}$ or Germany, ${ }^{66}$ and it was suggested that "hot spots" in F9 prone to mutation might account for the higher prevalence of certain variants.

Mosaicism is the presence of cell lines with different genotypes appearing in various tissues in an individual. ${ }^{67}$ It may be somatic or germline or both; either can have implications for reproductive outcomes. Somatic mosaicism for $\mathrm{HB}$ has been reported among both males and females. Mosaicism in leukocyte DNA was found in $11 \%$ of 45 individuals studied with sensitive techniques. ${ }^{68}$ Only cases with extremely low levels of mosaicism are likely to affect tests based on DNA isolated from leukocytes. However, somatic mosaicism may cause misinterpretation of phenotype. In three cases, men thought to have normal or mildly decreased FIX were actually mosaic for $\mathrm{HB}$ variants that appeared as severe or moderate HB when fully expressed in their affected grandchildren. ${ }^{69-71}$ In a family study, the mother of a sporadic $\mathrm{HB}$ male and her four sisters had the same $F 9$ haplotype but only the mother showed an HB-causing variant, which was also present in leukocyte DNA from the maternal grandmother on the haplotype inherited by all the sisters, suggesting that the grandmother had germline mosaicism. ${ }^{72}$ The birth of a second HB son when leukocyte DNA appeared normal has been reported. ${ }^{73}$ Additional testing of other tissues and with more sensitive methods has been advocated for mothers of sporadic cases; ${ }^{74}$ however, in some individuals, germline mutations may be present without variants in other tissues. This limits the ability to completely rule out heterozygosity by DNA analysis in blood and warrants a caveat in communication of test results.

\section{Genetic Counseling and Reproductive Options}

The development of sophisticated DNA analysis techniques has simplified the detection of heterozygotes in families transmitting $\mathrm{HB}$ yet has revealed the genetic complexity of the disease with its large number of pathogenic variants and potential for mosaicism and affected females. Genetic counseling for women undergoing genetic testing and all heterozygotes determined from 
pedigree analysis includes discussion of these concepts and measurement of FIX level to assess bleeding risk. Communication of this complex information warrants the use of a skilled genetic counselor. There are many reproductive options. Preimplantation genetic diagnosis has been performed for $\mathrm{HB}^{75}$ and is an option in some countries. ${ }^{76}$ Prenatal diagnosis by chorionic villus biopsy or amniocentesis is widely available and may be considered for delivery management; it may require pretreatment in women with low FIX levels. Non-invasive testing of fetal cells present in maternal plasma has been performed for $\mathrm{HB}$ as early as 10 weeks of pregnancy, although it has been more successful later in pregnancy. ${ }^{77}$ Men with $\mathrm{HB}$ also need genetic counseling, including education about the genetics of their disease, their risk of affected grandsons, and the possibility that their daughters may have bleeding symptoms.

\section{Gene Therapy}

Gene therapy for HB was first performed successfully in 2011 using an adeno-associated viral (AAV) vector directed to the liver, which is the site of synthesis of FIX. It was complicated by anti-AAV immune response and low levels of expression but achieved 2-6\% levels of FIX over several years. $^{78}$ Subsequent trials using the variant FIX-Padua, which has increased FIX production, and altered vectors have produced average FIX levels of $25-47 \%$. $^{21}$ Thus, levels in the upper range of mild $\mathrm{HB}$ or the normal range can be achieved, altering the clinical phenotype. Clinical trials, including two in Phase 3, ${ }^{79}$ are ongoing, as are those in animal models to answer questions surrounding the durability of the response, the need for immunosuppression, dose required, inhibitor risk, long-term liver effects, germline integration, and applicability to affected females. ${ }^{21}$ In addition, cost-benefit analyses of this expensive therapy are being carried out, and educational efforts directed to physicians and patients have been developed. ${ }^{79}$

\section{Conclusions}

Understanding of the basic genetics of $\mathrm{HB}$ has contributed to clinical care by providing information leading to improved treatment, better testing, and more accurate information for patients and families.

\section{Acknowledgments}

The findings and conclusions in this report are those of the author and do not necessarily represent the official position of the Centers for Disease Control and Prevention.

\section{Disclosure}

The author reports no conflicts of interest in this work.

\section{References}

1. Castaman G, Matino D. Hemophilia A and B: molecular and clinical similarities and differences. Haematologica. 2019;104(9):1702-1709. doi:10.3324/haematol.2019.221093

2. Choo KH, Gould KG, Rees DJG, Brownlee GG. Molecular cloning of the gene for human anti-haemophilic factor IX. Nature. 1982;299 (5879):178-180. doi:10.1038/299178a0

3. Kurachi K, Davie EW. Isolation and characterization of a cDNA coding for human factor IX. Proc Natl Acad Sci USA. 1982;79 (21I):6461-6464. doi:10.1073/pnas.79.21.6461

4. Rallapalli PM, Kemball-Cook G, Tuddenham EG, Gomez K, Perkins SJ. An interactive mutation database for human coagulation factor IX provides novel insights into the phenotypes and genetics of hemophilia B. J Thromb Haemost. 2013;11(7):1329-1340. doi:10.11 $11 /$ jth. 12276

5. Li T, Miller CH, Payne AB, Hooper WC. The CDC Hemophilia B mutation project mutation list: a new online resource. Mol Genet Genomic Med. 2013;1(4):238-245. doi:10.1002/mgg3.30

6. Rosner F. Hemophilia in the Talmud and rabbinic writings. Ann Intern Med. 1969;70(4):833-837. doi:10.7326/0003-4819-70-4-833

7. Hilgartner MW. Historical Annotation. An account of an hemorrhagic disposition existing in certain families. Haemophilia. 1997;3: 154-157. doi:10.1046/j.1365-2516.1997.00050.x

8. Biggs R, Douglas AS, Macfarlane RG, et al. Christmas disease: a condition previously mistaken for haemophilia. Br Med J. 1952;2 (4799):1378-1382. doi:10.1136/bmj.2.4799.1378

9. Wright IS. Nomenclature of blood clotting factors; acceptance by the International Committee on nomenclature of four factors, their characteristics and international number. Can Med Assoc J. 1958;80 (8):659-661.

10. Rogaev EI, Grigorenko AP, Faskhutdinova G, Kittler ELW, Moliaka YK. Genotype analysis identifies the cause of the "royal disease." Science. 2009;326(5954):817. doi:10.1126/science.1180660

11. Kulkarni R, Soucie JM, Lusher J, et al. Sites of initial bleeding episodes, mode of delivery and age of diagnosis in babies with haemophilia diagnosed before the age of 2 years: a report from the Centers for Disease Control and Prevention's (CDC) Universal Data Collection (UDC) project. Haemophilia. 2009;15(6):1281-1290. doi:10.1111/j.1365-2516.2009.02074.x

12. Miller CH, Bean CJ. Genetic causes of haemophilia in women and girls. Haemophilia. 2021;27(2):e164-e179. doi:10.1111/hae.14186

13. Kitchen S, de Paula Careta F, de Lima Montalvão SA, et al. Laboratory diagnosis and monitoring. In: Srivastava A, Santagostino E, Dougall A, et al., editors. WFH Guidelines for the Management of Hemophilia, 3rd Edition. Haemophilia; 2020;26 (Suppl 6):29-54. doi:10.1111/hae.14046

14. Blanchette VS, Key NS, Ljung LR, et al. Definitions in hemophilia: communication from the SSC of the ISTH. J Thromb Haemost. 2014;12:1935-1939. doi:10.1111/jth.12672

15. Andrew M, Paes B, Milner R, et al. Development of the human coagulation system in the full-term infant. Blood. 1987;70 (1):165-172. doi:10.1182/blood.V70.1.165.165

16. Manco-Johnson MJ, Abshire TC, Shapiro AD, et al. Prophylaxis versus episodic treatment to prevent joint disease in boys with severe hemophilia. N Engl J Med. 2007;357(6):535-544. doi:10.1056/ NEJMoa067659

17. Chhabra A, Spurden D, Fogarty PF, et al. Real-world outcomes associated with standard half-life and extended half-life factor replacement products for treatment of haemophilia A and B. Blood Coagul Fibrinolysis. 2020;31(3):186-192. doi:10.1097/MBC.00000000000 00885 
18. Iorio A, Fischer K, Blanchette V, et al. Tailoring treatment of haemophilia B: accounting for the distribution and clearance of standard and extended half-life FIX concentrates. Thromb Haemost. 2017;117 (6):1023-1030. doi:10.1160/TH16-12-0942

19. Shapiro AD, Ragni MV, Borhany M, et al. Natural history study of factor IX deficiency with focus on treatment and complications (B-Natural). Haemophilia. 2021;27(1):49-59. doi:10.1111/hae.14139

20. Buckner TW, Bocharova I, Hagan K, et al. Health care resource utilization and cost burden of hemophilia B in the United States. Blood Adv. 2021;5(7):1950-1962. doi:10.1182/bloodadvances.2020003424

21. Arruda VR, Weber J, Samelson-Jones BJ. Gene therapy for inherited bleeding disorders. Semin Thromb Haemost. 2021;47(2):161-173. doi:10.1055/s-0041-1722862

22. Mannucci PM, Franchini M. Is haemophilia B less severe than haemophilia A? Haemophilia. 2013;19(4):499-502. doi:10.1111/ hae. 12133

23. Quick AJ, Hussey CV. Hemophilia B (PTC deficiency, or Christmas disease). AMA Arch Intern Med. 1959;103(5):762-775. doi:10.1001/ archinte.1959.00270050084014

24. Soucie JM, Miller CH, Dupervil B, Le B, Buckner TW. Occurrence rates of haemophilia among males in the United States based on surveillance conducted in specialized haemophilia treatment centres. Haemophilia. 2020;26(3):487-493. doi:10.1111/hae.13998

25. Puetz J, Soucie JM, Kempton CL, Monahan PE. Prevalent inhibitors in haemophilia B subjects enrolled in the Universal Data Collection database. Haemophilia. 2013;20(1):25-31. doi:10.1111/hae.12229

26. Warrier I, Ewenstein BM, Koerper MA, et al. Factor IX inhibitors and anaphylaxis in haemophilia B. Haemophilia. 1996;2(4):259-260. doi:10.1111/j.1365-2516.1996.tb00149.x

27. Ewenstein BM, Takemoto C, Warrier I, et al. Nephrotic syndrome as a complication of immune tolerance in hemophilia B. Blood. 1997;89 (3):1115-1116. doi:10.1182/blood.V89.3.1115

28. Collins PW, Chalmers E, Hart D, et al. Diagnosis and management of acquired coagulation inhibitors: a guideline from UKHCDO. $\mathrm{Br}$ $J$ Haematol. 2013;162(6):758-773. doi:10.1111/bjh.12463

29. DiMichele DM, Kroner BL. The North American Immune Tolerance Registry: practices, outcomes, outcome predictors. Thromb Haemost. 2002;87(1):52-57. doi:10.1055/s-0037-1612943

30. Iorio A, Stonebraker JS, Chambost H, et al. Establishing the prevalence and prevalence at birth of hemophilia in males a meta-analytic approach using national registries. Ann Intern Med. 2019;171 (8):542-546. doi:10.7326/M19-1208

31. Stonebraker JS, Bolton-Maggs PHB, Soucie JM, Walker I, Brooker M. A study of variations in the reported haemophilia B prevalence around the world. Haemophilia. 2012;18(3):e91-e94. doi:10.1111/j.1365-2516.2011.02588.x

32. Gomez K, Laffan M, Keeney S, Sutherland M, Curry N, Lunt P. Recommendations for the clinical interpretation of genetic variants and presentation of results to patients with inherited bleeding disorders A UK Haemophilia Centre Doctors' Organisation Good Practice Paper. Haemophilia. 2019;25(1):116-126. doi:10.1111/hae.13637

33. Kasper CK, Lin JC. Prevalence of sporadic and familial haemophilia. Haemophilia. 2007;13(1):90-92. doi:10.1111/j.1365-2516.2006.01 397.x

34. Yoshitake S, Schach BG, Foster DC, Davie EW, Kurachi K. Complete nucleotide sequences of the gene for human factor IX (antihemophilic factor B). Biochemistry. 1985;24(14):3736-3750. doi:10.1021/bi00335a049

35. Roberts HR, Cederbaum AI. The liver and blood coagulation: physiology and pathology. Gastroenterology. 1972;63(2):297-320. doi:10.1016/S0016-5085(19)33318-9

36. Richards S, Aziz N, Bale S, et al. Standards and guidelines for the interpretation of sequence variants: a joint consensus recommendation of the American College of Medical Genetics and Genomics and the Association for Molecular Pathology. Genet Med. 2015;17 (5):405-424. doi:10.1038/gim.2015.30
37. Briet E, Bertina RM, van Tilburg NH, Veltkamp JJ. Hemophilia B Leyden: a sex-linked hereditary disorder that improves after puberty. $N$ Engl J Med. 1982;306(13):788-790. doi:10.1056/ NEJM198204013061306

38. Ahmed SZ, O’Rourke M, Jenkins V, Regan I, Nolan B. Progressive increase in FIX level in males with haemophilia B Leyden and c. $35 \mathrm{G}>\mathrm{A}$ mutation in early childhood not related to androgen effect. Br J Haematol. 2020;189(6):e262-e265. doi:10.1111/bjh.16688

39. Lavin M, Jenkins PV, Healy ML, Byrne M, O’Connell NM, O'Donnell JS. Age-related factor IX correction in symptomatic female carriers with haemophilia B Leyden. Haemophilia. 2015;21 (6):e498-e500. doi:10.1111/hae.12761

40. DiMichele DM, Gibb C, Lefkowitz JM, Ni Q, Gerber LM, Ganguly A. Severe and moderate haemophilia A and B in US females. Haemophilia. 2014;20(2):e136-e143. doi:10.1111/ hae. 12364

41. Chaudhury A, Sidonio R Jr, Jain N, et al. Women and girls with haemophilia and bleeding tendencies: outcomes related to menstruation, pregnancy, surgery and other bleeding episodes from a retrospective chart review. Haemophilia. 2021;27(2):293-304. doi:10.1111/hae.14232

42. James PD, Mahlangu J, Bidlingmaier C, et al. Evaluation of the utility of the ISTH-BAT in haemophilia carriers: a multinational study. Haemophilia. 2016;22(6):912-918. doi:10.1111/hae.13089

43. Payne AB, Bean CJ, Hooper WC, Miller CH. Utility of multiplex ligation-dependent probe amplification (MLPA) for hemophilia mutation screening. $J$ Thromb Haemost. 2012;10(9):1951-1954. doi:10.1111/j.1538-7836.2012.04843.x

44. Miller CH, Soucie JM, Byams VR, et al. Women and girls with haemophilia receiving care at specialized haemophilia treatment centres in the United States. Haemophilia. 2021. doi:10.1111/hae.14403

45. Karimipoor M, Kokabee L, Kamali E, Karizi SZ, Zeinali S. Molecular analysis of factor IX gene in an Iranian female with severe hemophilia B. Acta Haematol. 2008;119(3):151-153. doi:10.1159/ 000128043

46. Costa JM, Vidaud D, Laurendeau I, et al. Somatic mosaicism and compound heterozygosity in female hemophilia B. Blood. 2000;96 (4):1585-1587. doi:10.1182/blood.V96.4.1585.h8001585_1585_1587

47. Kelsey G, Monagle P, Barnes C. Delayed diagnosis of congenital factor IX deficiency (Christmas disease) in a girl with Turner's syndrome. Clin Lab Haematol. 2006;28(5):355-356. doi:10.1111/ j.1365-2257.2006.00810.x

48. Chan DWK, Lam JCM. Young girl with bruising: finding the $\mathrm{X}$ factor. J Paediatr Child Health. 2019;55(4):465-467. doi:10.1111/ jpc. 14282

49. Stoof SCM, Kersseboom R, de Vries FAT, Kruip MJHA, Kievit AJA, Leebeek FWG. Hemophilia B in a female with intellectual disability caused by a deletion of Xq26.3q28 encompassing the F9. Mol Genet Genomic Med. 2018;6(6):1220-1224. doi:10.1002/mgg3.425

50. Janczar S, Babol-Pokora K, Jatczak-Pawlik I, et al. Puzzling outcome of the nationwide genetic survey of severe/moderate female haemophilia B in Poland. Haemophilia. 2019;25(6):e373-e376. doi:10. 1111/hae. 13854

51. Krepischi-Santos ACV, Carneiro JDA, Svartman M, Bendit I, OdoneFilho V, Vianna-Morgante AM. Deletion of the factor IX gene as a result of translocation $\mathrm{t}(\mathrm{X} ; 1)$ in a girl affected by haemophilia $\mathrm{B}$. $\mathrm{Br}$ $J$ Haematol. 2001;113(3):616-620. doi:10.1046/j.1365-2141.2001. 02786.x

52. Sellner LN, Price PJ. Segmental isodisomy and skewed $\mathrm{X}$-inactivation resulting in haemophilia $\mathrm{B}$ in a female. $\mathrm{Br}$ $J$ Haematol. 2005;131(3):410-411. doi:10.1111/j.1365-2141.2005. 05780.x

53. Schröder W, Wulff K, Wollina K, Herrmann FH. Haemophilia B in female twins caused by a point mutation in one factor IX gene and nonrandom inactivation patterns of the X-chromosomes. Thromb Haemost. 1997;78(5):1347-1351. doi:10.1055/s-0038-1665409 
54. Okumura K, Fujimori Y, Takagi A, et al. Skewed X chromosome inactivation in fraternal female twins results in moderately severe and mild haemophilia B. Haemophilia. 2008;14(5):1088-1093. doi:10.1111/j.1365-2516.2008.01786.x

55. Mason JA, Aung HT, Nandini A, et al. Demonstration of a novel Xp22.2 microdeletion as the cause of familial extreme skewing of X-inactivation utilizing case-parent trio SNP microarray analysis. Mol Genet Genomic Med. 2018;6(3):357-369. doi:10.1002/mgg3.378

56. Mason JA, Robertson JD. Extreme skewing of X-inactivation: rethinking severe haemophilia in women and girls. Haemophilia. 2019;25(4):e286-e287. doi:10.1111/hae.13755

57. Bicocchi MP, Migeon BR, Pasino M, et al. Familial nonrandom inactivation linked to the $\mathrm{X}$ inactivation centre in heterozygotes manifesting haemophilia A. Eur J Hum Genet. 2005;13(5):635-640. doi:10.1038/sj.ejhg.5201386

58. Haldane JBS. On the rate of spontaneous mutation of a human gene. J Genet. 1935;31:317-326. doi:10.1007/BF02982403

59. Haldane JB. The mutation rate of the gene for haemophilia, and its segregation ratios in males and females. Ann Eugen. 1947;13 (4):262-271. doi:10.1111/j.1469-1809.1946.tb02367.x

60. Green PM, Saad S, Lewis CM, Giannelli F. Mutation rates in humans. I. Overall and sex-specific rates obtained from a population study of hemophilia B. Am J Hum Genet. 1999;65 (6):1572-1579. doi:10.1086/302651

61. Ketterling RP, Vielhaber E, Bottema CDK, et al. Germ-line origins of mutation in families with hemophilia B: the sex ratio varies with the type of mutation. Am J Hum Genet. 1993;52(1):152-166.

62. Ketterling RP, Bottema CDK, PhillipsJA III, Sommer SS. Evidence that descendants of three founders constitute about $25 \%$ of hemophilia B in the United States. Genomics. 1991;10(4):1093-1096. doi:10.1016/0888-7543(91)90207-U

63. Thorland EC, Weinshenker BG, Liu JZ, et al. Molecular epidemiology of factor IX germline mutations in Mexican Hispanics: pattern of mutation and potential founder effects. Thromb Haemost. 1995;74 (6):1416-1422. doi:10.1055/s-0038-1649957

64. Jenkins VV, Egan H, Keenan C, et al. Mutation analysis of haemophilia B in the Irish population: increased prevalence caused by founder effect. Haemophilia. 2008;14(4):717-722. doi:10.1111/ j.1365-2516.2008.01765.x

65. Ljung R, Petrini P, Tengborn L, Sjörin E. Haemophilia B mutations in Sweden: a population-based study of mutational heterogeneity. $\mathrm{Br}$ J Haematol. 2001;113(1):81-86. doi:10.1046/j.1365-2141.2001.02759.x

66. Knobloch O, Zoll B, Zerres K, Brackmann HH, Olek K, Ludwig M. Recurrent mutations in the factor IX gene: founder effect or repeat de novo events - Investigation of the German haemophilia B population and review of de novo mutations. Hum Genet. 1993;92(1):40-48. doi:10.1007/BF00216143

67. Youssoufian H, Pyeritz RE. Mechanisms and consequences of somatic mosaicism in humans. Nat Rev Genet. 2002;3(10):748-758. doi: $10.1038 / \operatorname{nrg} 906$
68. Ketterling RP, Vielhaber E, Li X, et al. Germline origins in the human F9 gene: frequent $\mathrm{G}: \mathrm{C} \rightarrow \mathrm{A}: \mathrm{T}$ mosaicism and increased mutations with advanced maternal age. Hum Genet. 1999;105(6):629-640. doi: $10.1007 / \mathrm{s} 004390051155$

69. Cutler JA, Mitchell MJ, Smith MP, Savidge GF. Germline mosaicism resulting in the transmission of severe hemophilia B from a grandfather with a mild deficiency. Am J Med Genet. 2004;129A (1):13-15. doi:10.1002/ajmg.a.30162

70. Kasper CK, Buzin CH. Mosaics and haemophilia. Haemophilia. 2009;15(6):1181-1186. doi:10.1111/j.1365-2516.2009.02003.x

71. Taylor SAM, Deugau KV, Lillicrap DP. Somatic mosaicism and female-to-female transmission in a kindred with hemophilia B (factor IX deficiency). Proc Natl Acad Sci USA. 1991;88 (1):39-42. doi:10.1073/pnas.88.1.39

72. Sommer SS, Knöll A, Greenberg CR, Ketterling RP. Germline mosaicism in a female who seemed to be a carrier by sequence analysis. Hum Mol Genet. 1995;4(11):2181-2182. doi:10.1093/hmg/4.11.2181

73. Kim HJ, Lee KO, Yoo KY, Kim SH, Kim HJ. Maternal low-level somatic mosaicism of Cys155Tyr of F9 in severe hemophilia B. Blood Coagul Fibrinolysis. 2015;26(8):866-868. doi:10.1097/ MBC.0000000000000234

74. Lannoy N, Hermans C. Genetic mosaicism in haemophilia: a practical review to help evaluate the risk of transmitting the disease. Haemophilia. 2020;26(3):375-383. doi:10.1111/hae.13975

75. Perez J, Lucena E, Hughes M, Lizcano L, Kasper CK. Preimplantation genetic diagnosis-a historical annotation: first PGD baby turns fifteen. Haemophilia. 2011;17(Suppl 1):18-19. doi:10.1111/j.1365-2516.2011.02560.x

76. Peyvandi F, Garagiola I, Mortarino M. Prenatal diagnosis and preimplantation genetic diagnosis: novel technologies and state of the art of PGD in different regions of the world. Haemophilia. 2011;17(Suppl 1):14-17. doi:10.1111/j.13652516.2011.02559.x

77. Hudecova I, Jiang P, Davies J, Lo YMD, Kadir RA, Chiu RWK. Noninvasive detection of $F 8$ int22h-related inversions and sequence variants in maternal plasma of hemophilia carriers. Blood. 2017;130 (3):340-347. doi:10.1182/blood-2016-12-755017

78. Nathwani AC. Gene therapy for hemophilia. Hematology Am Soc Hematol Educ Program. 2019;2019(1):1-8. doi:10.1182/ hematology.2019000007

79. Pipe SW. Delivering on the promise of gene therapy for haemophilia. Haemophilia. 2021;27(S3):114-121. doi:10.1111/hae.14027

80. UCL. Factor IX Gene (F9) Variant Database. Available from: http:// www.factorix.org/statistics.html.php. Accessed November 07, 2021.

81. Centers for Disease Control and Prevention. CHBMP F9 Database. Available from: https://www.cdc.gov/ncbddd/hemophilia/champs. html. Accessed October 19, 2021.
The Application of Clinical Genetics

\section{Publish your work in this journal}

The Application of Clinical Genetics is an international, peerreviewed open access journal that welcomes laboratory and clinical findings in the field of human genetics. Specific topics include: Population genetics; Functional genetics; Natural history of genetic disease; Management of genetic disease; Mechanisms of genetic disease;

\section{Dovepress}

Counselling and ethical issues; Animal models; Pharmacogenetics Prenatal diagnosis; Dysmorphology. The manuscript management system is completely online and includes a very quick and fair peerreview system, which is all easy to use. Visit http://www.dovepress. com/testimonials.php to read real quotes from published authors. 